\title{
Intravenous C-Arm Conebeam CT Angiography following Long-Term Flow-Diverter Implantation: Technologic Evaluation and Preliminary Results
}

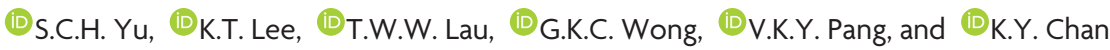

\begin{abstract}
BACKGROUND AND PURPOSE: A noninvasive investigation with high spatial resolution and without metal artifacts is necessary for long-term imaging follow-up after flow-diverter implantation. We aimed to evaluate the diagnostic value of conebeam CT angiography with intravenous contrast enhancement in the assessment of vascular status following implantation of the Pipeline Embolization Device and to analyze the preliminary results of vascular status following long-term Pipeline Embolization Device implantation.
\end{abstract}

MATERIALS AND METHODS: This was an ongoing prospective study of consecutive patients with intracranial aneurysms treated with the Pipeline Embolization Device. Patients with a modified Rankin Scale score of 4-5 were excluded. The median and interquartile range of the time interval of Pipeline Embolization Device implantation to conebeam CT angiography with intravenous contrast enhancement were 56.6 and 42.9-62.4 months, respectively. Conebeam CT angiography with intravenous contrast enhancement was performed with the patient fully conscious, by using a C-arm CT with a flat panel detector.

RESULTS: There were 34 patients and 34 vascular segments. In all 34 cases, contrast effect and image quality were good and not substantially different from those of intra-arterial conebeam CTA. Metal artifacts occurred in all 14 cases with coil masses; the Pipeline Embolization Device was obscured in 3 cases. In all 34 cases, there was no residual aneurysm, no vascular occlusion, 1 vascular stenosis (50\%), good Pipeline Embolization Device apposition to the vessel, and no Pipeline Embolization Device-induced calcification. All 28 Pipeline Embolization Device-covered side branches were patent.

CONCLUSIONS: Conebeam CT angiography with intravenous contrast enhancement is potentially promising and useful for effective evaluation of the vascular status following intracranial flow diverters. The Pipeline Embolization Device for intracranial aneurysms is probably safe and promising for long-term placement, with favorable morphologic outcome and without delayed complications.

ABBREVIATIONS: $\mathrm{CBCT}=$ conebeam $\mathrm{CT}$; $\mathrm{CBCTA}=$ conebeam $\mathrm{CT}$ angiography; $\mathrm{IACBCTA}=$ conebeam $\mathrm{CT}$ angiography with intra-arterial contrast enhancement; IVCBCTA = conebeam CT angiography with intravenous contrast enhancement; PED = Pipeline Embolization Device

$\mathbf{T}$ he Pipeline Embolization Device (PED; Covidien, Irvine, California) as a flow diverter has been introduced for the treatment of intracranial aneurysms. ${ }^{1-6}$ To date, knowledge on the anatomic status of the post-PED vascular segment as revealed on DSA is mainly limited to within 6-12 months. ${ }^{1,2,4,5,7,8}$ Follow-up DSA with a longer duration of 18-24 months has been reported in only 2 studies. ${ }^{6,9}$ Beyond 24 months, post-PED

Received April 28, 2015; accepted after revision July 29.

From the Department of Imaging and Interventional Radiology (S.C.H.Y., K.T.L., T.W.W.L.) and Division of Neurosurgery (G.K.C.W.), Department of Surgery, The Chinese University of Hong Kong, Prince of Wales Hospital, Shatin, Hong Kong SAR; Department of Neurosurgery (V.K.Y.P.), Pamela Youde Nethersole Eastern Hospital, Hong Kong, SAR; and Department of Neurosurgery (K.Y.C.), Kwong Wah Hospital, Yaumatei, Kowloon, Hong Kong, SAR.

This research was supported by funding from the Vascular and Interventional Radiology Foundation. vascular status has been studied only with $\mathrm{MR}$ imaging, ${ }^{10}$ but CT angiography or MR angiography is not desirable for this purpose owing to metal artifacts from the PED and suboptimal spatial resolution. ${ }^{11,12}$ The long-term status of the post-PED vascular segment and the covered side branches beyond 24 months remains unknown. The use of DSA to assess long-term post-PED vascular status is probably not practical because patients tend to refuse an invasive investigation when they do not see an immediate clinical need; such limitations could be an important cause of lack of long-term angiographic data. There

Please address correspondence to Simon Chun Ho Yu, MBBS, MD, FRCR, Department of Imaging and Interventional Radiology, The Chinese University of Hong Kong, Room 2A061; Department of Imaging and Interventional Radiology, Level 2, Main Clinical Block; and Trauma Centre, Prince of Wales Hospital, 30-32 Ngan Shing St, Shatin, Hong Kong SAR; e-mail: simonyu@cuhk.edu.hk

http://dx.doi.org/10.3174/ajnr.A4558 
is, therefore, a need for a noninvasive technique with multiplanar cross-sectional imaging capability for simultaneous visualization of the PED and the vessel lumen, to allow adequate examination of the PED-paved vascular segment.

The use of conebeam CT angiography with intravenous contrast enhancement (IVCBCTA) for patient monitoring following placement of flow diverters has been reported and found to be feasible and potentially useful. ${ }^{13-15}$ We aimed to evaluate the diagnostic value of IVCBCTA in the assessment of post-PED vascular status and to analyze the preliminary results of vascular status following long-term PED implantation.

\section{MATERIALS AND METHODS Study Design}

This was part of a prospective study that aimed to evaluate the long-term radiologic outcome of PED implantation. The study had been approved by the institutional review board, conducted in accordance to the Declaration of Helsinki and the International Conference on Harmonisation Good Clinical Practice. Consecutive patients with intracranial aneurysms treated with the PED between September 2008 and December 2011 were invited to participate in this study according to the chronologic order of the date of PED implantation. Patients who gave consent to the study were included. Patients with a modified Rankin Scale score of 4 or 5 at the time of this study, between October and December of 2014, were excluded because it is unethical to overburden this group of patients with an investigation that does not directly benefit them; moreover, the increased risk of motion artifacts due to the increased likelihood of restlessness and noncompliance among these patients was also a concern. The study objectives were to evaluate the diagnostic value of IVCBCTA in the assessment of postPED vascular status and to analyze the preliminary results of vascular status following long-term PED implantation.

\section{Imaging Protocol}

The patients were positioned supine with the head placed on a rubber head mold for stability. The patient's head and the rubber mold were bound to the floating tabletop with 3 external immobilization straps set on the forehead and mandible. The contrast arrival time from the right antecubital vein to the cervical carotid arteries was predetermined specifically for each individual patient with a test dose of $15 \mathrm{~mL}$ of iohexol (Omnipaque, $350 \mathrm{mg} \mathrm{I/mL;} \mathrm{GE} \mathrm{Healthcare,} \mathrm{Piscataway,} \mathrm{New}$ Jersey) delivered at $4 \mathrm{~mL} / \mathrm{s}$ through an 18 -ga catheter by using a power injector. DSA was performed at 1 frame/s in the frontal projection. Before conebeam CT (CBCT), $80 \mathrm{~mL}$ of Omnipaque, $350 \mathrm{mg} \mathrm{I} / \mathrm{mL}$, was injected at a rate of $4 \mathrm{~mL} / \mathrm{s}$. CBCT scanning was activated following contrast injection at a time lag equivalent to the contrast arrival time. CBCT was performed by using biplane DSA equipment (Allura FD20/20; Philips Healthcare, Best, the Netherlands) that consisted of a C-arm-mounted CT unit and a digital flat panel detector. A nontruncated CT volume was created at a detector format of 48 $\mathrm{cm}$, a projection matrix of $1024 \times 792$ pixels without pixel binning, $2464 \times 1904$ photodiodes, scintillator thickness of $550-\mu \mathrm{m}$, scanning time of 20 seconds, 622 projections, an ac- quisition range of $240^{\circ}$, and $0.38^{\circ}$ angular increment. The detector entrance-dose setting was $149.0 \mathrm{nGy} /$ projection. The respective raw data were transferred to the XperCT (Philips Healthcare) workstation for reconstruction. At the default zoom factor of $140 \%$ and default resolution of $384^{3}$, voxels of $467 \mu \mathrm{m}^{3}$ were created at a pixel pitch of $254 \mu \mathrm{m}$. A second reconstruction on a specific area of interest was performed at $33 \%$ zoom and $384^{3}$ resolution to create voxels of $65 \mu \mathrm{m}^{3}$. Reconstruction took approximately 30 seconds. The isotropic volume data of the PED-paved vascular segment were displayed at a thickness of $0.2-0.27 \mathrm{~mm}$, examined at multiplanar cross-sectional projections, and included the longitudinal and axial sections of the vascular segment, with manipulation of the parameters of metal or soft-tissue algorithms. 3D imaging was used to define the location of the PED in relation to bone structures, the location of embolization coils in relation to the PED, and the orientation of beam-hardening artifacts in relation to the PED.

\section{Control Conebeam CT Angiography with Intra-Arterial Contrast}

The image quality of IVCBCTA was evaluated by comparing IVCBCTA with conebeam CTA with intra-arterial contrast enhancement (IACBCTA), which was performed on another date in 10 randomly selected patients as a control. The IACBCTA was performed with the internal carotid artery or the proximal vertebral artery catheterized for contrast delivery and the patient under general anesthesia. Omnipaque, $30 \mathrm{mg} \mathrm{I} / \mathrm{L} 40 \mathrm{~mL}$, was delivered with a power injector at $2 \mathrm{~mL} / \mathrm{s}$ for 20 seconds. The scanning time was 20 seconds. The difference in image quality of IVCBCTA compared with IACBCTA was evaluated by 2 neuroradiologists who were blinded to the nature of the images and drew conclusions by consensus. Each of the 10 pairs of conebeam CT angiography (CBCTA) images was rated as "no difference or subtle difference" or "substantial difference" regarding the quality of contrast enhancement, motion artifacts, and metal artifacts due to the PED. Interobserver agreement on the ratings was estimated with $\kappa$ statistics. ${ }^{16}$

\section{Study Subjects}

There were 34 patients, including 12 men and 22 women. The average age was $61.9 \pm 10.3$ years. The mean, median, and interquartile range of PED insertion to IVCBCTA time interval was 54.2 $\pm 11.3,56.6$, and 42.9-62.4 months, respectively. Thirty-four vascular segments were involved, 32 of them located at the internal carotid artery C2-3, C3-4, C4-5, C6, or C4-6. The other 2 were located at segments 3-4 of the vertebral artery. Seven vascular segments were covered with 2 PEDs, and 27 segments were covered with 1 PED. In 28 of these 34 cases, 1 or 2 side branches were covered by the PED; in total, 32 side branches were covered. In 11 of these 34 vascular segments that had been treated with the PED for cerebral aneurysms, coil embolization had been performed for the same cerebral aneurysm. The average aneurysm size was $7 \pm 5.3 \mathrm{~mm}$. IVCBCTA was successfully completed in all 34 patients without adverse effects. 

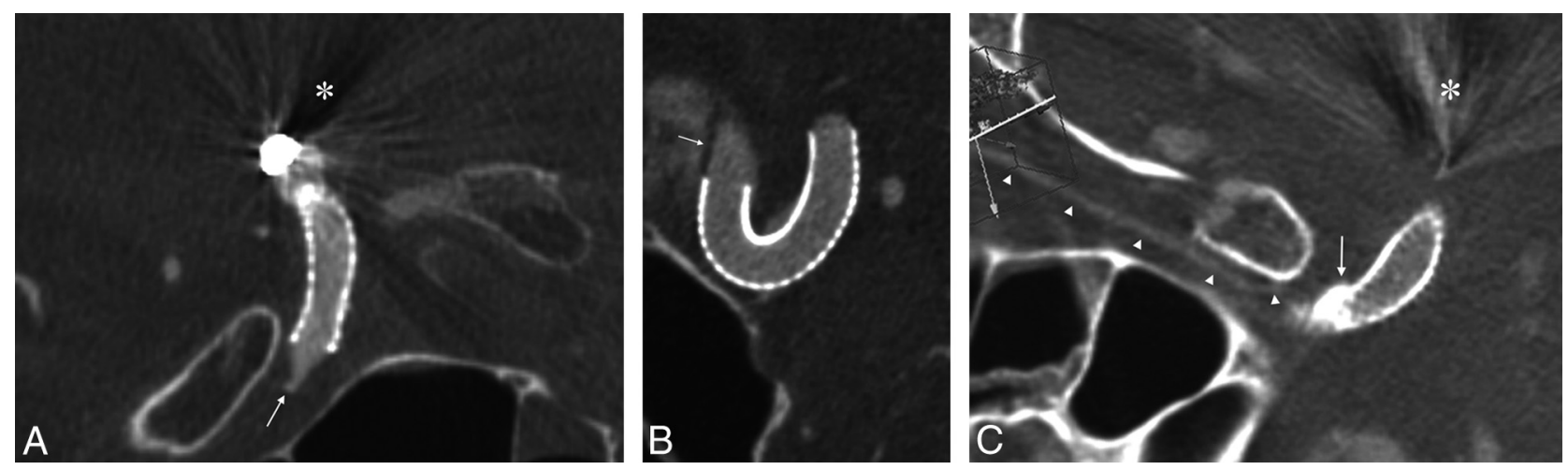

FIG 1. CBCTA with intra-arterial contrast shows the absence of motion artifacts and good contrast opacification of the vascular structures. The same image quality is also observed with IVCBCTA. A, Metal artifacts (asterisk) and the origin of ophthalmic artery (white arrow) are depicted on intra-arterial CBCTA. $B$, Features of contrast enhancement within the internal carotid artery and the hypoattenuated wall of the internal carotid artery (white arrow) within the enhanced cavernous sinus are indistinguishable from those depicted on intravenous CBCTA. C, In a 59-year-old man who underwent implantation of 1 PED 68 months ago, IVCBCTA shows the presence of metal artifacts (white asterisk) not affecting the PED-paved vascular segment to be assessed. Focal calcification can be depicted near the lower end of the PED (white arrow). The ophthalmic artery covered by the PED is well-preserved and well-depicted (white arrowheads).

\section{Study Parameters}

The study end points for the diagnostic value of IVCBCTA included the quality of intravascular contrast that was rated as "good" or "suboptimal," the presence of motion artifacts, and the presence of metal artifacts due to the PED. The study end points for post-PED vascular status included the presence of residual aneurysms, the presence of vascular occlusion or stenosis, good PED apposition to vessel wall without any gapping, the presence of intimal calcification of the PED-paved segment, and the patency of the PED-covered vascular branch. Imaging findings were reviewed by 2 neuroradiologists who drew conclusions by consensus. Interobserver agreement on the evaluation of the diagnostic value of CBCTA and post-PED vascular status was estimated with the $\kappa$ statistics. ${ }^{16}$

\section{Statistical Analysis}

Descriptive statistics were performed on the variables of patient demographics, the time interval of PED implantation to IVCBCTA, and all the study parameters. Interobserver agreement on the rating of the image quality of IVCBCTA compared with IACBCTA, the evaluation of the diagnostic value of CBCTA, and the evaluation of the post-PED vascular status was estimated with $\kappa$ statistics, in which a $\kappa$ value of $0.81-0.99$ signified almost perfect agreement. ${ }^{16}$

\section{RESULTS}

\section{Comparison of IVCBCTA and IACBCTA}

In the 10 pairs of images, there was no substantial difference between IVCBCTA and IACBCTA regarding the quality of contrast enhancement, motion artifacts, and metal artifacts due to the PED (Fig 1). There was perfect agreement between the 2 neuroradiologists on the ratings.

\section{Diagnostic Value of CTA}

In all 34 cases, the quality of the intravascular contrast effect of IVCBCTA was good $(\kappa=1)$ and there were no motion artifacts $(\kappa=1)$ (Table). In all 20 cases in which there were no embolization coils in the cerebral aneurysm, metal artifacts were not present $(\kappa=1)$. In all 14 cases in which embolization coils were

\section{Study results}

\begin{tabular}{|c|c|c|}
\hline $\begin{array}{c}\text { Study End Points } \\
\text { (Total No. of Cases for Assessment) }\end{array}$ & Result & $\kappa$ \\
\hline \multicolumn{3}{|l|}{ Diagnostic value of IVCBCTA } \\
\hline Good contrast quality (34) & $34(100 \%)$ & 1 \\
\hline Motion artifacts present (34) & 0 & 1 \\
\hline \multicolumn{3}{|l|}{$\begin{array}{l}\text { Obscuration of PED-paved segment } \\
\text { due to metal artifact }\end{array}$} \\
\hline Embolization coil present (14) & 3 & 1 \\
\hline Embolization coil absent (20) & 0 & 1 \\
\hline \multicolumn{3}{|l|}{ Post-PED vascular status } \\
\hline Presence of residual aneurysm (31) & 0 & 1 \\
\hline Presence of vascular occlusion (31) & 0 & 1 \\
\hline Presence of vascular stenosis (31) & $1(3.2 \%)$ & 1 \\
\hline $\begin{array}{l}\text { Good PED apposition to vessel } \\
\text { wall (31) }\end{array}$ & $31(100 \%)$ & 1 \\
\hline $\begin{array}{l}\text { Intimal calcification of the PED-paved } \\
\text { segment (31) }\end{array}$ & 0 & 1 \\
\hline Patency vascular branch (28) & $28(100 \%)$ & 1 \\
\hline
\end{tabular}

present, metal artifacts were present $(\kappa=1)$. The metal artifacts were due to the coil mass, extended from the coil mass, and were orientated in the plane parallel to the direction of $\mathrm{x}$-ray beams (Fig 2). In 3 of these 14 cases, all or part of the PED-paved vascular segment was oriented within the plane of metal artifacts and was obscured by the metal artifacts so that the status of these vascular segments could not be assessed. In the other 11 cases with metal artifacts due to the coil mass, the PED-paved vascular segment could still be well-depicted on CBCT $(\kappa=1)$ (Fig 2).

\section{Post-PED Vascular Status}

Apart from the 3 vascular segments that were obscured by metal artifacts, all of the other 31 vascular segments could be assessed with IVCBCTA for vascular status (Table). There was no evidence of residual aneurysms in all 31 cases $(\kappa=1)$ (Fig 3). Vascular occlusion was absent in all cases $(\kappa=1)$. Vascular stenosis of any degree occurred in only 1 case in a 79-year-old man 40 months after PED implantation $(\kappa=1)$. The stenosis was $46 \%$ (residual lumen, $1.4 \mathrm{~mm}$; normal segment, $2.6 \mathrm{~mm}$ ) and was located at the distal end of the PED at C6 of the internal carotid artery (Fig 4). The PED was well-apposed to the vessel wall and conformed to 

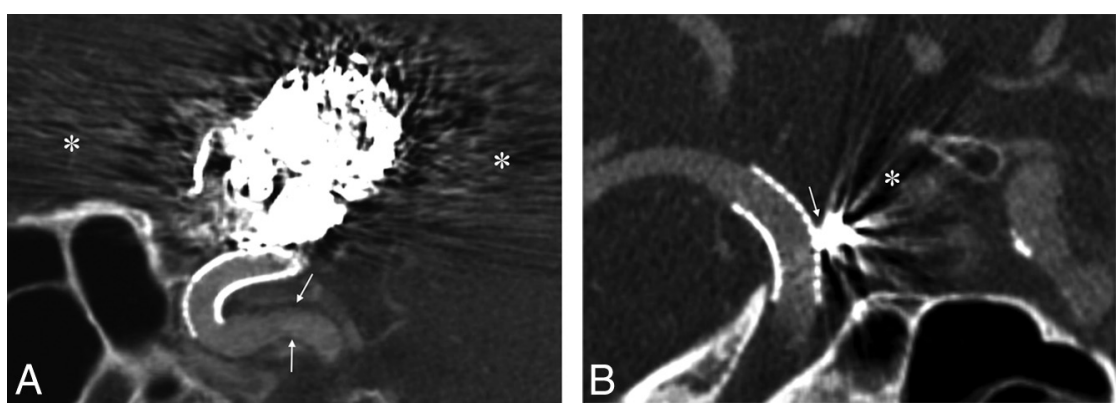

FIG 2. How the PED-paved vascular segment can still be depicted in the presence of coil-induced metal artifacts is illustrated in the following 2 cases. $A$, In a 67-year-old woman who had a giant aneurysm at C6 and received coil embolization 4 times with 23 coils (total length, $275 \mathrm{~cm}$ ), including 1 stent-assisted coil embolization, the aneurysm recurred and was treated with 2 PEDs implanted at C4-6. IVCBCTA was performed 55 months after PED implantation. Although the large coil mass in close proximity induced intense metal artifacts, the PED-paved vascular segment is not affected because it lies outside the plane of metal artifacts (white asterisks) parallel to the direction of the conebeam x-ray. The PED is seen well-apposed to the vessel wall and conforming to the vascular curvature. The hypoattenuated wall of the internal carotid artery (white arrow) allows the vessel to be differentiated from the contrast-enhanced cavernous sinus. $B$, In a 57-year-old man who underwent coil embolization (total length, $20 \mathrm{~cm}$ ) for a cerebral aneurysm and subsequently underwent PED implantation at C6 for aneurysm recurrence, IVCBCTA was performed 72 months afterward, which showed the PED-paved vascular segment unaffected by metal artifacts (white asterisk), despite the presence of the coil mass (white arrow) in close proximity. The PED is seen well-apposed to the vessel wall and conforming to the vascular curvature.
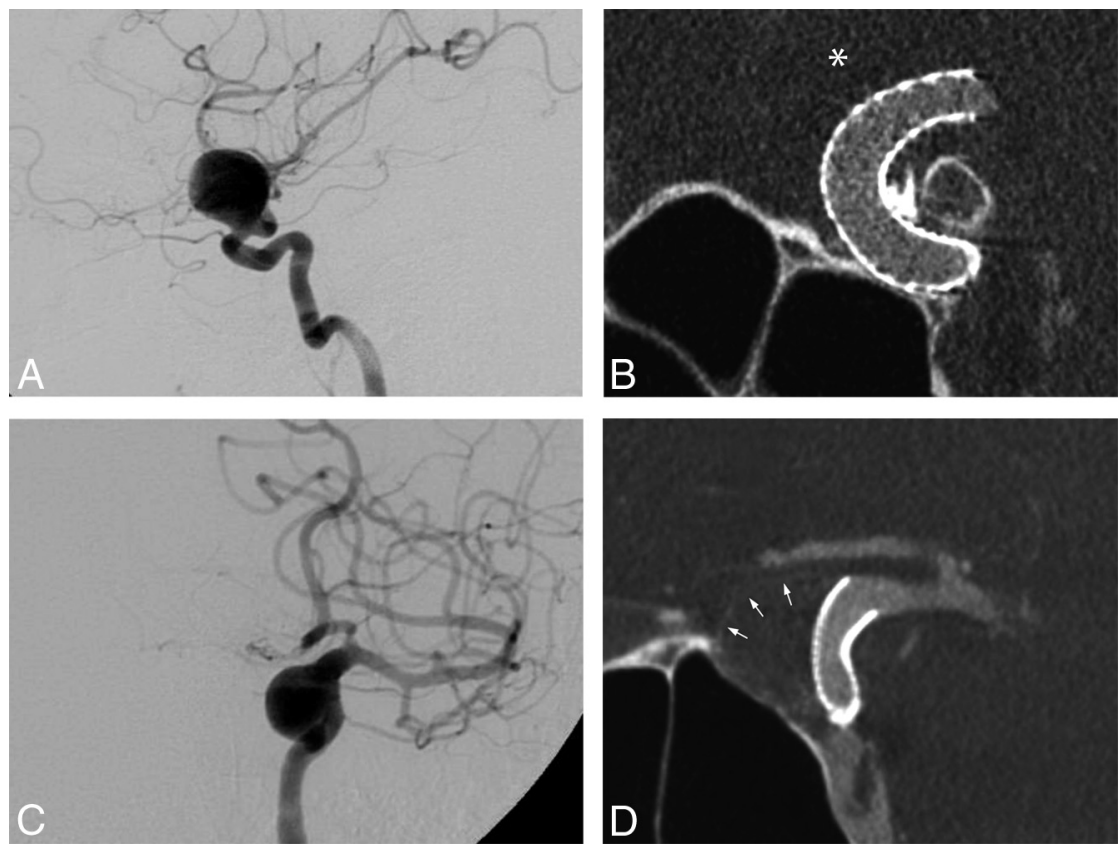

FIG 3. In a 68-year-old woman with a 21-mm saccular aneurysm located at the ophthalmic segment (C6) of the internal carotid artery as shown on DSA (A), follow-up IVCBCTA 56 months after PED implantation shows no evidence of residual cavity or wall of the aneurysm (white asterisk, B). In a 69-year-old woman with a 13-mm saccular aneurysm located at the communicating segment (C7) of the internal carotid artery as shown on DSA (C), follow-up IVCBCTA 52 months after PED shows no evidence of a residual cavity of the aneurysm but evidence of a residual wall of the aneurysm (white arrows, D).

the vascular curvature in all cases $(\kappa=1)$ (Fig 5). Focal calcification of $2-4.4 \mathrm{~mm}$ in length occurred in 5 cases, all located at the vessel wall outside the PED $(\kappa=1)$ (Figs $2 C$ and $5 A,-B)$. Calcifications occurred bilaterally at corresponding sites in all 5 cases. All were present on the plain CT before PED implantation. These features signified atherosclerotic calcification rather than PEDinduced calcification. Four of 32 PED-covered side branches were obscured by metal artifacts, and their patency could not be assessed; all of the other 28 PED-covered side branches were patent $(\kappa=1)$ (Figs $2 C$ and $5 B-D)$.

\section{DISCUSSION}

Compared with multidetector row CT, CBCT can provide superior spatial resolution, which is distinctly advantageous for imaging intracranial vessels, especially those with calcified atherosclerotic plaques, cerebral aneurysms, and endovascular stents. ${ }^{17,18}$ CBCT has a similar contrast resolution for high-contrast structures but a slightly inferior contrast resolution for low-contrast structures compared with multidetector row CT, though the difference is negligible for most clinical applications. ${ }^{17,19}$ The radiation dose of CBCT for the head is generally lower than that of multidetector row $\mathrm{CT} .{ }^{20}$ For example, in sinus imaging, the effective radiation doses of CBCT and multidetector row CT were 0.17 and $0.87 \mathrm{mSv}$, respectively. ${ }^{18}$ However, the image noise in CBCT images was $54.8 \%-70.6 \%$ higher than that in multidetector row CT images. ${ }^{19} \mathrm{CT}$ number uniformity and accuracy were also worse with the CBCT scanner. ${ }^{21}$

Noncontrast CBCT has been used for intraoperative monitoring of neuroendovascular interventional procedures $^{22,23}$; it was found useful for visualization and characterization of intracranial stents that are notoriously low-profile and radiopaque. ${ }^{24}$ In-stent restenosis, calcified plaque, and stentvessel interface that are not visualized by radiography or DSA can be depicted with CBCT. ${ }^{24}$

Intra-arterial CBCTA has been used to image intracranial stents and was found to be useful in simultaneous imaging of the stent and the parent vessel. ${ }^{25}$ In the assessment of the degree of in-stent restenosis following a nitinol stent, intra-arterial CBCTA was found to correlate well with histology in an in vivo swine experiment. Intracranial CBCTA also correlated well with DSA in assessing in-stent restenosis following intracranial stents or PEDs in clinical studies. ${ }^{26}$ The accuracy of intra-arterial CBCTA in assessing the status of PED apposition to the vessel wall has been validated with catheter-based optical coherence tomography endoscopy in in vivo canine models. ${ }^{27}$ The use of IVCBCTA as a noninvasive imaging alternative for the assessment of the 

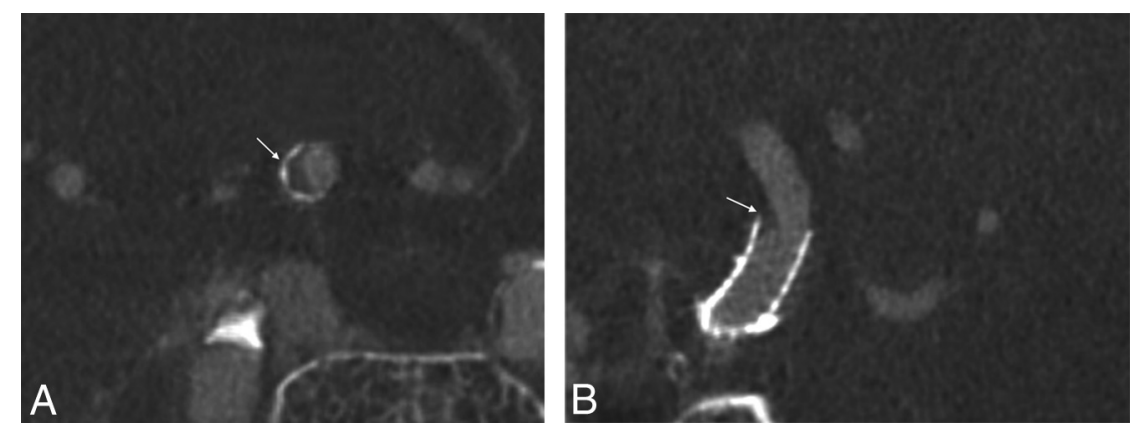

FIG 4. The only case of vascular stenosis occurred in a 79-year-old man who underwent implantation of 1 PED at 40 months before IVCBCTA. The stenosis (white arrow) can be well-depicted between the PED and the contrast-enhanced arterial lumen when the vascular segment C6 is examined in cross-sections perpendicular to the long axis $(A)$ or in a longitudinal section $(B)$.
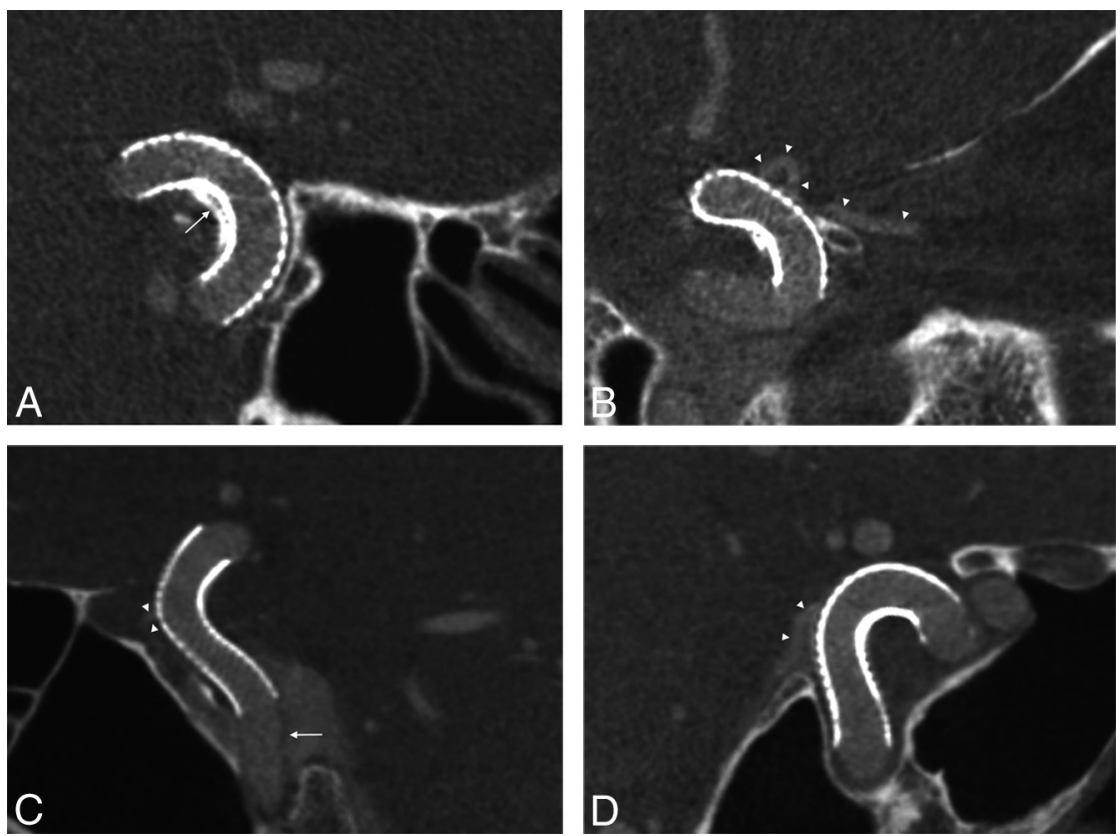

FIG 5. Good PED apposition to the vessel wall, good PED conformity to the vascular curvature, and preservation of the covered side branch can be illustrated in the following 3 patients. In a 66-year-old woman who underwent implantation of 1 PED 42 months ago, IVCBCTA ( $A$ ) shows good PED apposition to the vessel wall and good conformity to the vascular curvature, with focal calcification at the wall of C5 outside the PED (white arrow). B, Good PED apposition to the vessel wall and focal calcification are shown again at another cross-sectional plane, in which the ophthalmic artery covered by the PED is well-preserved and well-depicted (white arrowheads). C, In a 68-year-old woman who underwent implantation of 1 PED 52 months ago, IVCBCTA shows good PED apposition to the vessel wall and good conformity to the vascular curvature. The hypoattenuated wall of the internal carotid artery (white arrow) allows the vessel to be differentiated from the contrast-enhanced cavernous sinus. $D$, In an 81-year-old woman who underwent implantation of 1 PED 51 months ago, IVCBCTA shows good PED apposition to the vessel wall and good conformity to the vascular curvature. The ophthalmic artery covered by the PED is wellpreserved and well-depicted (white arrowheads).

vascular status following flow diverters is an attractive idea that has been put into practice recently. ${ }^{13-15}$

To date, the experience of intravenous CBCTA on the assessment of flow diverters is still very limited; it is restricted to 14 patients in 3 reports. ${ }^{13-15}$ In 2 of these reports that originated from the same group, IVCBCTA was acquired with a 10-second program (Axion Artis dBA, Siemens AG, Healthcare Sector, Forchheim, Germany). ${ }^{13,14}$ In the other report, a 20 -second program (Allura FD20/20; Philips Healthcare), the same as that being used in the current study, was used. ${ }^{15} \mathrm{~A}$ longer acquisition time of 20 seconds instead of 10 seconds allows a better image signal producing a better image quality, while there is an increased chance of image-quality degradation due to motion artifacts, especially in the absence of general anesthesia.

The results of the current study showed that with the use of a 20-second program (Allura FD20/20; Philips Healthcare), the contrast effect of IVCBCTA was good and not substantially different from that of IACBCTA in assessing PED-paved vascular segments. Despite a long acquisition time of up to $20 \mathrm{sec}-$ onds, the images could be free of motion artifacts with the use of external immobilization straps, which was demonstrated consistently in all 34 patients without exception.

The problem of motion artifacts due to long acquisition times could likely be solved. We, therefore, believe that intravenous CBCTA is potentially a promising technique useful for effective evaluation of intracranial vessels following implantation of flow diverters in an outpatient setting without general anesthesia. However, metal artifacts due to beam-hardening, scattered radiation, sampling, and noise artifacts remain a problem in CBCT in the presence of embolization coils. ${ }^{25}$ When the ROI is located in proximity to the coils and becomes obscured by metal artifacts, the diagnostic value of CBCT is greatly diminished, though the presence of a coil mass in close proximity to a vascular segment does not necessarily preclude the possibility of good-quality imaging of the vascular segment with IVCBCTA, provided the vascular segment is oriented outside the plane of metal artifacts when CT is performed. The possibility of good quality imaging of the vascular segment despite the presence of metal artifacts was demonstrated in 11 of 14 patients with intracranial coil masses (Fig 2). If the location of the coil mass in relation to the PEDpaved vascular segment can be identified and taken into account in the positioning of the patient's head in relation to the $\mathrm{x}$-ray beam for CBCTA, the detrimental effect of metal artifacts on the CT image of the vascular segment can be reduced. Moreover, techniques to reduce metal artifacts due to the coil mass in CBCT are being developed. ${ }^{28,29}$

The post-PED vascular status following long-term PED implantation has been evaluated in 34 cases by using intravenous CBCTA as part of an ongoing study. These preliminary results 
showed very promising outcomes of complete aneurysm occlusion in all cases, absence of parent artery occlusion, a low stenosis (46\% stenosis) rate of $3.2 \%$ (1/31), complete PED apposition to vessel wall in all cases, absence of PED-induced calcification, and absence of occlusion of the PED-covered side branch. These findings indicated very favorable morphologic outcome and absence of delayed complications following long-term PED placement.

The small number of cases in the current report was a limitation for the assessment of post-PED vascular status; there was also a selection bias in patients with modified Rankin Scale scores of 4 or 5 . We present these early findings because we believe the findings are conclusive and unlikely to differ significantly when the entire ongoing study is completed.

\section{CONCLUSIONS}

IVCBCTA is potentially a promising technique that is useful for effective evaluation of the status of intracranial arteries following implantation of flow diverters; the PED for intracranial aneurysms is probably promising and safe for long-term placement, with very favorable morphologic outcome without delayed complications.

Disclosures: Vincent Kai Yuen Pang—UNRELATED: Expert Testimony: preparing an expert report about a case (potential medicolegal case); Travel/Accommodations/ Meeting Expenses Unrelated to Activities Listed: Pamela Youde Nethersole Eastern Hospital Doctors Association (source: MicroVention), Comments: travel to AsianAustralasian Federation of Interventional and Therapeutic Neuroradiology in 2014, European Congress of Neurological Surgery in 2014

\section{REFERENCES}

1. Lylyk P, Miranda C, Ceratto R, et al. Curative endovascular reconstruction of cerebral aneurysms with the Pipeline embolization device: the Buenos Aires experience. Neurosurgery 2009;64:632-42; discussion 642-3; quiz N6 CrossRef Medline

2. Szikora I, Berentei Z, Kulcsar Z, et al. Treatment of intracranial aneurysms by functional reconstruction of the parent artery: the $\mathrm{Bu}$ dapest experience with the Pipeline embolization device. AJNR Am J Neuroradiol 2010;31:1139-47 CrossRef Medline

3. Nelson PK, Lylyk P, Szikora I, et al. The Pipeline embolization device for the intracranial treatment of aneurysms trial. Am J Neuroradiol AJNR 2011;32:34-40 CrossRef Medline

4. Fischer S, Vajda Z, Aguilar Perez M, et al. Pipeline embolization device (PED) for neurovascular reconstruction: initial experience in the treatment of 101 intracranial aneurysms and dissections. Neuroradiol 2012;54:369-82 CrossRef Medline

5. McAuliffe W, Wycoco V, Rice $\mathrm{H}$, et al. Immediate and midterm results following treatment of unruptured intracranial aneurysms with the Pipeline embolization device. AJNR Am J Neuroradiol 2012; 33:164-70 CrossRef Medline

6. Yu SCH, Kwok CK, Cheng PW, et al. Intracranial aneurysms: midterm outcome of Pipeline embolization-a prospective study in 143 patients with 178 aneurysms. Radiology 2012;265:893-901 CrossRef Medline

7. Zanaty M, Chalouhi N, Tjoumakaris SI, et al. Flow-diversion panacea or poison? Front Neurol 2014;5:21 CrossRef Medline

8. Gascou G, Lobotesis K, Brunel H, et al. Extra-aneurysmal flow modification following Pipeline embolization device implantation: focus on regional branches, perforators, and the parent vessel. AJNR Am J Neuroradiol 2015;36:725-31 CrossRef Medline

9. Saatci I, Yavuz K, Ozer C, et al. Treatment of intracranial aneurysms using the Pipeline flow-diverter embolization device: a single-center experience with long-term follow-up results. AJNR Am J Neuroradiol 2012;33:1436-46 CrossRef Medline

10. Briganti F, Napoli M, Leone G, et al. Treatment of intracranial an- eurysms by flow diverter devices: long-term results from a single center. Eur J Radiol 2014;83:1683-90 CrossRef Medline

11. Curtin KR, Walker MT, Shaibani A. Appearance of the Neuroform stent on computed tomography angiographic images: imaging pitfall-case illustration. J Neurosurg 2007;107:1249 CrossRef Medline

12. Lövblad KO, Yilmaz H, Chouiter A, et al. Intracranial aneurysm stenting: follow-up with MR angiography. J Magn Reson Imaging 2006;24:418-22 CrossRef Medline

13. Struffert T, Saake M, Ott S, et al. Intravenous flat detector CT angiography for non-invasive visualisation of intracranial flow diverter: technical feasibility. Eur Radiol 2011;21:1797-801 CrossRef Medline

14. Saake M, Struffert T, Goelitz P, et al. Angiographic CT with intravenous contrast agent application for monitoring of intracranial flow diverting stents. Neuroradiology 2012;54:727-35 CrossRef Medline

15. Kizilkilic O, Kocer N, Metaxas GE, et al. Utility of VasoCT in the treatment of intracranial aneurysm with flow-diverter stents. J Neurosurg 2012;117:45-49 CrossRef Medline

16. Viera AJ, Garrett JM. Understanding interobserver agreement: the kappa statistic. Fam Med 2005;37:360-63 Medline

17. Gupta R, Cheung AC, Bartling SH, et al. Flat-panel volume CT: fundamental principles, technology, and applications. Radiographics 2008;28:2009-22 CrossRef Medline

18. Miracle AC, Mukherji SK. Conebeam CT of the head and neck, part 2: clinical applications. AJNR Am J Neuroradiol 2009;30:1285-92 CrossRef Medline

19. Bai M, Liu B, Mu H, et al. The comparison of radiation dose between C-arm flat-detector CT (DynaCT) and multi-slice CT (MSCT): a phantom study. Eur J Radiol 2012;81:3577-80 CrossRef Medline

20. Mettler FA Jr, Huda W, Yoshizumi TT, et al. Effective doses in radiology and diagnostic nuclear medicine: a catalog. Radiology 2008; 248:254-63 CrossRef Medline

21. Yu L, Vrieze TJ, Bruesewitz MR, et al. Dose and image quality evaluation of a dedicated cone-beam CT system for high-contrast neurologic applications. AJR Am J Roentgenol 2010;194:W193-201 CrossRef Medline

22. Engelhorn T, Struffert T, Richter G, et al. Flat panel detector angiographic $\mathrm{CT}$ in the management of aneurysmal rupture during coil embolization. AJNR Am J Neuroradiol 2008;29:1581-84 CrossRef Medline

23. Pfaff J, Struffert T, Gölitz P, et al. Angiographic CT for intraprocedural monitoring of complex neuroendovascular procedures. AJNR Am J Neuroradiol 2013;34:E77-80 CrossRef Medline

24. Benndorf G, Strother CM, Claus B, et al. Angiographic CT in cerebrovascular stenting. AJNR Am J Neuroradiol 2005;26:1813-18 Medline

25. Patel NV, Gounis MJ, Wakhloo AK, et al. Contrast-enhanced angiographic cone-beam CT of cerebrovascular stents: experimental optimization and clinical application. AJNR Am J Neuroradiol 2011;32: 137-44 CrossRef Medline

26. Flood TF, van der Bom IM, Strittmatter L, et al. Quantitative analysis of high-resolution, contrast-enhanced, cone-beam CT for the detection of intracranial in-stent hyperplasia. J Neurointerv Surg 2015; 7:118-25 CrossRef Medline

27. van der Marel K, Gounis M, King R, et al. P-001 high-resolution optical and angiographic CT imaging of flow-diverter stents for assessment of vessel wall apposition. J Neurointerv Surg 2014; 6(suppl 1):A21 CrossRef

28. Psychogios MN, Scholz B, Rohkohl C, et al. Impact of a new metal artefact reduction algorithm in the noninvasive follow-up of intracranial clips, coils, and stents with flat-panel angiographic CTA: initial results. Neuroradiology 2013;55:813-18 CrossRef Medline

29. van der Bom IM, Hou SY, Puri AS, et al. Reduction of coil mass artifacts in high-resolution flat detector conebeam CT of cerebral stent-assisted coiling. AJNR Am J Neuroradiol 2013;34:2163-70 CrossRef Medline 